\title{
ANALISIS KEBUTUHAN SUMBER DAYA MANUSIA BAGIAN PENYIMPANAN BERKAS REKAM MEDIS DENGAN MENGGUNAKAN METODE BEBAN KERJA GUNA MENUNJANG EFEKTIVITAS KERJA DI RUMAH SAKIT AL-ISLAM BANDUNG
}

\author{
M Dana Prihadi' \\ Akademi Perekam Medis Dan Informatika Kesehatan Bandung \\ danaprihadi@apikesbandung.ac.id \\ Rana Agustian ${ }^{2}$ \\ Akademi Perekam Medis Dan Informatika Kesehatan Bandung \\ agustianrana@apikesbandung.ac.id
}

\begin{abstract}
Abstrak - Semakin tinggi dan besarnya pasien yang berkunjung pada rumah sakit, secara langsung berdampak pada beban kerja daripada karyawan dan yang sangat merasakan dampak hal tersebut adalah bagian rekam medis. Tujuan dilakukannya penelitian ini adalah 1) Mengetahui jumlah dan kualifikasi sumber daya manusia bagian penyimpanan berkas rekam medis di Rumah Sakit Al-Islam Bandung.2) Mengetahui efektivitas kerja di Rumah Sakit Al-Islam Bandung. 3) Mengetahui permasalahan yang timbul dalam perhitungan sumber daya manusia bagian penyimpanan rekam medis di Rumah Sakit Al-Islam Bandung.4) Mengetahui upayaupaya yang dapat dilakukan pihak rumah sakit untuk mengatasi masalah kebutuhan sumber daya manusia bagian penyimpanan berkas rekam medis menggunakan metode beban kerja guna menunjang efektivitas kerja di Rumah Sakit Al-Islam Bandung. Metode penelitian ini menggunakan metode analisis kualitatif, teknik pengumpulan data yang digunakan adalah observasi, wawancara terhadap uraian tugas petugas penyimpanan berkas rekam medis dan studi pustaka sesuai pokok permasalahan. Dalam perencanaan kebutuhan tenaga pada penelitian ini digunakan rumus dan perhitungan Work Load Indicator of Staff Need (WISN), yang merupakan metode menghitung kebutuhan SDM kesehatan berdasar pada beban kerja nyata tiap kategori SDM kesehatan. Berdasarkan hasil penelitian yang dilakukan, penulis menemukan dan menyimpulkan diantara-Nya jumlah petugas di bagian penyimpanan berkas rekam medis ada pengurangan yang awalnya 8 orang menjadi 2 orang dengan beban kerja yang telah di hitung menggunakan analisis beban kerja wisn berdasarkan uraian tugas yang ada hasilnya di bagian penyimpanan hanya memerlukan 1 orang saja untuk menunjang kegiatan penyimpanan.
\end{abstract}

Kata kunci: sumber daya manusia, rekam medis, beban kerja, efektivitas kerja

Abstract - The higher and the number of patients visiting the hospital, it directly affects the workload of employees and the one who really feels the impact of this is the medical 
record. The objectives of this research are 1) Knowing the number and qualifications of human resources in the storage of medical record files at the Al-Islam Hospital Bandung. 2) Knowing the effectiveness of work at Al-Islam Hospital Bandung. 3) Knowing the problems that arise in calculating human resources in the medical record storage section at the Al-Islam Hospital Bandung. 4) Knowing the efforts that the hospital can take to solve the problem of human resource needs in the medical record file storage section using the load method work to support the effectiveness of work at the Al-Islam Hospital Bandung. This research method uses qualitative analysis methods, data collection techniques used are observation, interviews with medical record storage clerk job descriptions and literature studies according to the subject matter. The work load indicator of staff need (WISN) is used in planning the workforce requirements in this study, which is a method of calculating the needs of health human resources based on the actual workload carried out by each category of health human resources. Based on the results of the research carried out, the authors found and concluded that, among them the number of officers in the storage section of the medical record files, there was a reduction from 8 people to 2 people with the workload that was calculated using domestic workload analysis based on job descriptions, the results were in the storage section only. requires only 1 person to support storage activities.

Keywords: human resources, medical records, workload, work effectiveness

\section{PENDAHULUAN}

Rumah Sakit adalah sebuah tempat berupa fasilitas kesehatan dengan tujuan memberikan pelayanan khususnya kesehatan menyeluruh dan mengutamakan penyembuhan sebagai hasil akhir dengan dilaksanakan secara terpadu dalam upaya memberikan peningkatan kesehatan serta pencegahan penyakit yang serta dapat dimanfaatkan untuk pendidikan tenaga dan penelitian (Mulyani, 2017). Rumah Sakit juga merupakan institusi yang dapat memberi keteladanan dalam budaya hidup bersih dan sehat serta kebersihan lingkungan. Di dalam Rumah Sakit terdapat Unit yang bergerak menangani Berkas Riwayat penyakit Pasien yaitu unit rekam medis (Budi, 2011).

Salah satu fungsi rumah sakit
adalah untuk menyelenggarakan
pelayanan pengobatan dan pemulihan
kesehatan sesuai dengan standar
pelayanan rumah sakit (Cahyono, 2015).
Seiring berkembangnya jaman, kini masyarakat sangat mudah untuk berobat ke rumah sakit. Dengan terciptanya asuransi-asuransi kesehatan, biaya perawatan di rumah sakit akan lebih terjangkau. Hal tersebut membuat jumlah kunjungan pasien bertambah banyak dari waktu ke waktu. Bertambahnya jumlah kunjungan pasien tentu berpengaruh terhadap profesionalisme dan beban kerja sumber daya manusia yang tersedia di rumah sakit.

Rumah Sakit Al-Islam Bandung adalah Salah satu sarana pelayanan kesehatan yang di dalamnya terdapat unit rekam medis. Pada unit Rekam Medis Rumah Sakit Al-Islam Bandung dilakukan kegiatan pengelolaan rekam medis yang terdiri dari proses penataan berkas rekam medis, pemberian kode diagnosa penyakit, analisa kuantitatif rekam medis, penyimpanan rekam medis, peminjaman rekam medis dan pengembalian berkas rekam medis.

Berdasarkan pengamatan di bagian penyimpanan Rumah sakit Al-Islam Bandung terlihat ada 2 pegawai filing 
dimana terdapat kendala berkas yang menumpuk, ke tidak imbangan dengan dokumen rekam medis yang masuk ke bagian filing serta banyak waktu kosong di waktu bekerja.

\section{KAJIAN LITERATUR}

Rekam medis adalah sekumpulan data, pengobatan tindakan, catatan, dokumen pasien, pemeriksaan serta pelayanan kesehatan lainnya yang telah diterima oleh pasien (Giyana, 2012). Menurut (Budi, 2011) rekam medis merupakan data rekaman lengkap yang di dalamnya terdapat catatan mengenai data diri pasien secara lengkap termasuk data penyakit, Tindakan dokter, hasil anamnesa kesehatan pasien yang dilakukan selama rentang waktu perawatan termasuk hasil akhir dari perawatan pasien. Menurut (Hatta, 2012) Rekam medis adalah berkas yang berisikan tulisan dan dokumen tentang data pasien, pemeriksaan, proses berobat, perlakuan tindakan medis, dan layanan lainnya yang diterima pasien pada unit pelayanan kesehatan. Pendapat lain mengatakan Rekam medis merupakan informasi tertulis dan terekam tentang identitas data pasien, anamnesa, pemeriksaan, laboratorium, diagnosa, serta seluruh kegiatan layanan dan aktivitas keputusan medis yang diberikan kepada pasien, termasuk pengobatan (rawat inap, rawat jalan maupun gawat darurat) (Murniwati, 2012). Rekam medis merupakan salah satu bagian terpenting dalam penyelenggaraan pelayanan kesehatan, karena tanpa rekam medis rumah sakit atau pelayanan kesehatan lainnya tidak akan berjalan dengan baik. Aktivitas rekam medis akan memiliki nilai baik apabila pada subbagian penyimpanan, pengolahan data dan pencatatan dilakukan dengan baik. (Rosyada et al., 2016).
Pada Permenkes 269 tahun 2008 pasal 7 menyebutkan "bahwa sarana pelayanan kesehatan wajib menyediakan fasilitas yang diperlukan dalam rangka penyelenggaraan rekam medis. Salah satu dari fasilitas yang diperlukan dalam rangka penyelenggaraan rekam medis adalah ruang penyimpanan dan rak penyimpanan berkas rekam medis". Terdapat enam hal terkait penyimpanan untuk dapat mengoptimalkan fungsi penyimpanan data dan informasi pelayanan pasien, yaitu kemudahan dalam akses, memiliki kualitas tinggi, terjamin keamanannya, fleksibilitas, mudah dalam sinkronisasi dengan semua sumber dan efisien (Hatta, 2012).

Menurut (Budi, 2011) ruang penyimpanan (filing) adalah salah satu bagian rekam medis yang memiliki tanggung jawab dalam penyimpanan dan pengembalian kembali dokumen rekam medis pasien. Tujuan penyimpanan dokumen rekam medis tersebut adalah memudahkan dan mengurangi waktu pencarian serta menemukan kembali dokumen pada rak penyimpanan, memberikan kemudahan pada saat pengambilan dari tempat penyimpanan, mudah meletakkan kembali dokumen, melindungi dokumen dari bahaya pencurian, bahaya kerusakan isik, kimiawi dan biologi. Penyimpanan adalah bagian dari unit yang berfungsi dalam melakukan penempatan dan pengaturan dokumen sesuai aturan tertentu dan sesuai prosedur tata penyimpanan dokumen rekam medis. Unit ini dinilai (akreditasi) langsung oleh Departemen Kesehatan

Pengertian sumber daya manusia menurut (Hasibuan, 2016) "ilmu dan seni mengatur hubungan dan peranan tenaga kerja agar efektif dan efisien membantu terwujudnya tujuan perusahaan, karyawan, dan masyarakat". SDM dalam setiap instansi merupakan pilar pertama dan utama. 
Sumber daya manusia kesehatan juga bisa dimaknai sebagai individu dengan kemampuan dan memiliki Pendidikan formal atau tidak, yang padanya memerlukan kewenangan melakukan upaya tindakan kesehatan (Mujiati \& Yuniar, 2016).

Salah satu metode perencanaan kebutuhan tenaga adalah Work Load Indicator Of Staff Need (WISN), metode ini merupakan perhitungan kebutuhan SDM kesehatan berdasarkan pada beban pekerjaan nyata yang dilaksanakan oleh tiap kategori SDM kesehatan (Ernawati et al., 2011). Metode ini memberikan kemudahan dalam penggunaan baik teknis dan non teknis, komprehensif dan realistis (Ernawati et al., 2011). Kualitas dan kuantitas sumber daya manusia harus sesuai dengan kebutuhan perusahaan termasuk rumah sakit supaya efektif dan efisien dalam menunjang tercapainya tujuan. Merencanakan kebutuhan sumber daya manusia secara baik agar tidak salah pilih dan dapat optimal dalam bekerja merupakan tantangan bagi rumah sakit. Untuk mengetahui dengan menganalisa kebutuhan tersebut dapat dilakukan dengan menggunakan metode WISN (Work Load Indicator Staff Need) (Rubbiana, 2015).

Efektivitas kerja adalah situasi lingkungan kerja yang menggambarkan ketercapaian tujuan yang telah ditetapkan sebelumnya dengan pengerahan seluruh kemampuan manusia pada aktivitasnya (Yudhaningsih, 2011). Hal itu merupakan permulaan dari keberhasilan suatu organisasi karena efektivitas individu akan menghasilkan efektivitas tingkat kelompok, efektivitas kelompok ini bergerak dalam suatu organisasi yang mempunyai tujuan yang sama (Apriani, 2011).

\section{METODE PENELITIAN}

Dalam penelitian ini, metode penelitian yang digunakan penulis adalah metode deskriptif dan analisa kualitatif yaitu menggambarkan fenomena yang terjadi dalam lapangan tanpa membuat hipotesa.

Pada teknik dan instrumen pengumpulan data, penulis menggunakan teknik sampling, wawancara, observasi dan studi kepustakaan. Pengukuran dan penghematan variabel penelitian secara deskriptif dengan cara menganalisis kebutuhan SDM bagian penyimpanan di Rumah Sakit Al-Islam Bandung. Penulis melakukan penelitian pada unit Rekam Medis Rumah Sakit Al-islam Bandung dimana ruang lingkupnya hanya pada permasalahan yang berhubungan dengan beban kerja dibagian penyimpanan berkas rekam medis.

Teknik Sampling merupakan teknik pengambilan sampel, teknik dalam penelitian ini yaitu menghitung jumlah beban kerja dibagian Penyimpanan Kebutuhan SDM = kuantitas kegiatan pokok+standar kelonggaran standar beban kerja

Wawancara adalah teknik
pengumpulan data dengan cara melakukan interviu langsung dengan informan yang berada pada rekam medis Rumah Sakit Al-Islam tentang beban kerja. Observasi biasanya diartikan sebagai pengamatan dan pencatatan dengan sistematis tentang fenomenafenomena yang diteliti, dengan demikian penulis melakukan pengamatan langsung kepada objek penelitian, kemudian dari hasil pengamatan tersebut dilakukan analisa masalah yang diteliti. Merupakan teknik pengumpulan data dengan cara mempelajari buku-buku dan berbagai literatur, serta teori-teori yang berkaitan dengan analisis beban kerja. Untuk teknik memverifikasi data, penulis mempelajari 
hasil dari perhitungan beban kerja. Dalam teknik atau prosedur pengolahan analisa data ini, penelitian menggunakan metode penelitian deskriptif analitik yaitu dengan melakukan penelitian sekaligus menganalisisnya, agar mendapatkan gambaran atau deskripsi sesuai dengan fenomena / kenyataan yang ada secara objektif.

\section{HASIL DAN PEMBAHASAN}

Hasil penelitian yang telah dilakukan di Rumah Sakit Al-Islam Bandung mengenai kebutuhan SDM, diperoleh hasil perhitungan uraian tugas dan kebutuhan tenaga kerja di unit penyimpanan berkas rekam medis Rumah Sakit Al-Islam Bandung sebagai berikut:

Tabel 1. Uraian Kegiatan Tenaga Rekam Medis Bagian Penyimpanan

\begin{tabular}{|c|c|c|c|c|}
\hline No & Kegiatan & Satuan & $\begin{array}{c}\text { Kuan } \\
\text { titas }\end{array}$ & $\begin{array}{l}\text { Rata-rata } \\
\text { Waktu } \\
\text { Per } \\
\text { kegiatan } \\
\text { (menit) }\end{array}$ \\
\hline 1 & $\begin{array}{l}\text { Mencetak } \\
\text { print out } \\
\text { Pasien RI }\end{array}$ & Pasien & 3 & 0,5 \\
\hline 2 & $\begin{array}{l}\text { Memasukan } \\
\text { printout yang } \\
\text { sudah di } \\
\text { cetak ke } \\
\text { dalam } \\
\text { tracer/pemba } \\
\text { tas/outguide } \\
\text { dan } \\
\text { menyusunny } \\
\text { a sesuai No } \\
\text { RM }\end{array}$ & Berkas & 3 & 0,5 \\
\hline 3 & $\begin{array}{l}\text { Mengambil } \\
\text { Berkas } \\
\text { Rekam } \\
\text { Medis dan } \\
\text { menggantiny } \\
\text { a dengan } \\
\text { tracer di rak } \\
\text { penyimpanan }\end{array}$ & $\begin{array}{c}\text { Berk } \\
\text { as }\end{array}$ & 4 & 0,5 \\
\hline 4 & $\begin{array}{l}\text { Mendistribusi } \\
\text { kan Berkas } \\
\text { Rekam } \\
\text { Medis Ke }\end{array}$ & $\begin{array}{c}\text { Berk } \\
\text { as }\end{array}$ & 4 & 7 \\
\hline
\end{tabular}

\begin{tabular}{|c|c|c|c|c|}
\hline & $\begin{array}{l}\text { Ruang } \\
\text { perawatan }\end{array}$ & & & \\
\hline 5 & $\begin{array}{l}\text { Pencarian } \\
\text { Berkas RM } \\
\text { Pasien } \\
\text { Rawat Inap } \\
\text { yang belum } \\
\text { di temukan di } \\
\text { rak } \\
\text { penyimpanan }\end{array}$ & $\begin{array}{c}\text { Berk } \\
\text { as }\end{array}$ & 2 & 15 \\
\hline 6 & $\begin{array}{l}\text { Menyusun } \\
\text { Berkas } \\
\text { Rekam } \\
\text { medis } \\
\text { berdasarkan } \\
\text { No Rekam } \\
\text { Medis }\end{array}$ & $\begin{array}{c}\text { Berk } \\
\text { as }\end{array}$ & 100 & 10 \\
\hline 7 & $\begin{array}{l}\text { Menerima } \\
\text { dan } \\
\text { mengkonfirm } \\
\text { asi unit } \\
\text { IRJ,RI, IRD } \\
\text { dan unit } \\
\text { lainnya } \\
\text { Mengenai } \\
\text { BRM yang di } \\
\text { butuhkan } \\
\text { Melalui } \\
\text { Telepon }\end{array}$ & $\begin{array}{c}\text { telep } \\
\text { on }\end{array}$ & 3 & 1 \\
\hline 8 & $\begin{array}{l}\text { Memperbaiki } \\
\text { Berkas RM } \\
\text { yang rusak }\end{array}$ & $\begin{array}{c}\text { Berk } \\
\text { as }\end{array}$ & 2 & 1 \\
\hline 9 & $\begin{array}{l}\text { Menyusun } \\
\text { Lembar } \\
\text { Rekam } \\
\text { Medis }\end{array}$ & $\begin{array}{c}\text { Berk } \\
\text { as }\end{array}$ & 60 & 30 \\
\hline 10 & $\begin{array}{l}\text { Menyusun } \\
\text { dan } \\
\text { Merapikan } \\
\text { Berkas } \\
\text { Rekam } \\
\text { Medis di Rak } \\
\text { Penyimpana } \\
\text { n }\end{array}$ & $\begin{array}{c}\text { Berk } \\
\text { as }\end{array}$ & 10 & 15 \\
\hline 11 & $\begin{array}{l}\text { Membuat } \\
\text { laporan } \\
\text { kegiatan } \\
\text { harian }\end{array}$ & kali & 1 & 5 \\
\hline
\end{tabular}

Berdasarkan hasil penelitian penulis di Rumah Sakit Al-Islam Bandung hari kerja dalam satu tahun adalah 278 hari (hari tersebut dalam setahun dan diselisih dengan hari libur nasional, cuti, ketidakhadiran kerja, dan lain-lain). Waktu kerja efektif dalam satu hari kerja 
adalah 7,5 jam. Dengan demikian, total waktu kerja tersedia selama satu tahun di Rumah Sakit Al-Islam Kota Bandung adalah 125.100 menit yang diperoleh berdasarkan perhitungan berikut. WISN

Perhitungan menggunakan rumus

a. Hari Kerja: 312 hari/tahun

b. Cuti Tahunan: 12 hari/tahun

c. Pendidikan dan Pelatihan: 3 hari/tahun

d. Hari Libur Nasional: 16 hari/tahun

e. Ketidak Hadiran Kerja: 3 hari/tahun

f. Waktu Kerja: 7,5 jam/hari

Waktu Kerja Tersedia

$=\{\mathrm{A}-(\mathrm{B}+\mathrm{C}+\mathrm{D}+\mathrm{E}) \times \mathrm{F}$

$=\{312-(12+3+16+3) \times 7,5$

$=\{312-34\} \times 7,5$

$=278 \times 7,5$

$=2085 \mathrm{Jam} /$ tahun

$=125.100$ menit/tahun

Standar beban kerja (SBK) merupakan kuantitas (volume) beban kerja selama satu tahun dan disusun berdasarkan waktu yang dibutuhkan dalam menyelesaikan kegiatan (rata- rata waktu) dan waktu yang tersedia pertahun yang dimiliki oleh setiap kategori tenaga.

Standar Beban Kerja =

waktu kerja tersedia

rata-rata waktu per kegiatan pokok

Tabel 2. Standar Beban Kerja per Kegiatan Pokok

\begin{tabular}{lll}
\hline No & Kegiatan & $\begin{array}{l}\text { Standar } \\
\text { Beban Kerja }\end{array}$ \\
\hline 1 & $\begin{array}{l}\text { Mencetak print out } \\
\text { Pasien RI }\end{array}$ & 250.200 \\
\hline 2 & $\begin{array}{l}\text { Memasukan printout yang } \\
\text { sudah di cetak ke dalam } \\
\text { tracer/pembatas/outguide } \\
\text { dan menyusunnya sesuai }\end{array}$ & \\
\hline 3 & No RM & \\
\hline 3 & Mengambil Berkas & 250.200 \\
& $\begin{array}{l}\text { Rekam Medis dan } \\
\text { menggantinya dengan } \\
\text { tracer di rak } \\
\text { penyimpanan }\end{array}$ & \\
\hline
\end{tabular}

\begin{tabular}{|c|c|c|}
\hline 4 & $\begin{array}{l}\text { Mendistribusikan Berkas } \\
\text { Rekam Medis Ke Ruang } \\
\text { perawatan }\end{array}$ & 17.871 \\
\hline 5 & $\begin{array}{l}\text { Mencari Berkas Rekam } \\
\text { medis Pasien Rawat Inap } \\
\text { yang belum di temukan di } \\
\text { rak penyimpanan }\end{array}$ & 8.340 \\
\hline 6 & $\begin{array}{l}\text { Menyusun Berkas Rekam } \\
\text { medis berdasarkan No } \\
\text { Rekam Medis }\end{array}$ & 12.510 \\
\hline 7 & $\begin{array}{l}\text { Menerima dan } \\
\text { mengkonfirmasi unit } \\
\text { IRJ,RI, IRD dan unit } \\
\text { lainnya Mengenai BRM } \\
\text { yang di butuhkan Melalui } \\
\text { Telepon }\end{array}$ & 125.100 \\
\hline 8 & $\begin{array}{l}\text { Memperbaiki Berkas } \\
\text { Rekam Medis yang } \\
\text { sudah rusak }\end{array}$ & 125.100 \\
\hline 9 & $\begin{array}{l}\text { Menyusun Lembar } \\
\text { Rekam Medis }\end{array}$ & 4.170 \\
\hline 10 & $\begin{array}{l}\text { Menyusun dan Merapikan } \\
\text { Berkas Rekam Medis di } \\
\text { Rak Penyimpanan }\end{array}$ & 8.340 \\
\hline 11 & $\begin{array}{l}\text { Membuat laporan } \\
\text { kegiatan harian }\end{array}$ & 25.020 \\
\hline
\end{tabular}

Berdasarkan tabel 2 di atas, diperoleh data standar beban kerja paling rendah adalah kegiatan mencetak data pasien rawat inap, memasukkan data yang sudah di cetak tersebut ke dalam tracer/pembatas/outguide dan menyusunnya sesuai nomor rekam medis, mengambil berkas rekam medis dan menggantinya dengan tracer di rak penyimpanan sebesar 250.200 menit/tahun. Hal ini menunjukkan bahwa kegiatan tersebut membutuhkan waktu 1/250.200 dari hari kerja tersedia dalam 1 tahun. Sedangkan standar beban kerja paling tinggi dengan nilai 4.170 menit/tahun adalah pada kegiatan menyusun lembar rekam medis. Artinya untuk menyusun lembar rekam medis petugas membutuhkan waktu 1/4.170 dari hari kerja tersedia dalam 1 tahun.

Standar kelonggaran harus ditetapkan untuk memperoleh kebutuhan waktu pada tiap kategori tenaga guna menyelesaikan faktor kelonggaran kegiatan yang tidak atau kurang terkait 
secara langsung dengan kebutuhan waktu pelaksanaan kegiatan pokok. Adapun rumusan perhitungan standar kelonggaran unit kerja rekam medis yaitu

Standar kelonggaran $=$

jumlah rata-rata waktu faktor kelonggaran

waktu kerja tersedia

Tabel 3. Standar Kelonggaran

\begin{tabular}{llllll}
\hline No & $\begin{array}{l}\text { Kegiat } \\
\text { an }\end{array}$ & $\begin{array}{l}\text { Satu } \\
\text { an }\end{array}$ & $\begin{array}{l}\text { Kua } \\
\text { ntita } \\
\text { s }\end{array}$ & $\begin{array}{l}\text { Waktu } \\
\text { per } \\
\text { menit }\end{array}$ & $\begin{array}{l}\text { Standa } \\
\text { kelong } \\
\text { garan }\end{array}$ \\
\hline 1 & Rapat & Kali & 12 & 120 & $\begin{array}{l}0,0009 \\
5923\end{array}$ \\
\hline 2 & $\begin{array}{l}\text { Kepani } \\
\text { tian }\end{array}$ & Kali & 2 & 300 & $\begin{array}{l}0,0023 \\
9808\end{array}$ \\
\hline & Jumlah & & & & 0,0033 \\
& & & & & 5731 \\
\hline
\end{tabular}

Berdasarkan tabel 3 diinformasikan bahwa terdapat standar kelonggaran sebesar 0,00335731. Hal tersebit dapat diartikan, setiap tenaga penyimpanan berkas rekam medis memiliki faktor kelonggaran sebesar 0,00335731 , atau dengan kata lain, masing-masing petugas menghabiskan waktu untuk menghadiri rapat atau kepanitiaan sebesar $0,00335731 \%$ dari total waktu kerja tersedia. Standar kelonggaran yang paling besar adalah menghadiri kepanitiaan dengan standar 0,00239808 atau $0,2 \%$ petugas dari total waktu kerja tersedia.

Kuantitas kegiatan pokok

$=$ Volume Kegiatan $\times \sum$ Hari Kerja Efektif dalam Setahun Keterangan Pasien Rawa inap/hari : 4 Pasien

$4 \times 278=1.112$

Perhitungan tenaga rekam medis tujuannya untuk memperoleh jumlah tenaga/sumber daya manusia dan jenis kualifikasi yang dibutuhkan untuk menyelenggarakan pelayanan atau pengelolaan rekam medis selama kurun waktu 1 tahun. Rumus perhitungannya sebagai berikut :

Kebutuhan SDM

kuantitas kegiatan pokok+standar kelonggaran standar beban kerja

Tabel 4. Kebutuhan SDM penyimpanan berkas rekam medis

\begin{tabular}{|c|c|c|}
\hline No & Kegiatan & Kebutuhan \\
\hline 1 & $\begin{array}{l}\text { Mencetak print out } \\
\text { Pasien RI }\end{array}$ & 0,00001200 \\
\hline 2 & $\begin{array}{l}\text { Memasukan printout yang } \\
\text { sudah di cetak ke dalam } \\
\text { tracer/pembatas } \\
\text { /outguide dan } \\
\text { menyusunnya sesuai No } \\
\text { RM }\end{array}$ & 0,00001200 \\
\hline 3 & $\begin{array}{l}\text { Mengambil Berkas } \\
\text { Rekam Medis dan } \\
\text { menggantinya dengan } \\
\text { tracer di rak } \\
\text { penyimpanan }\end{array}$ & 0,000016 \\
\hline 4 & $\begin{array}{l}\text { Mendistribusikan Berkas } \\
\text { Rekam Medis Ke Ruang } \\
\text { perawatan }\end{array}$ & 0,00022401 \\
\hline 5 & $\begin{array}{l}\text { Mencari berkas tekam } \\
\text { medis pasen rawat inap } \\
\text { (belum di temukan di rak } \\
\text { penyimpanan) }\end{array}$ & 0,00024021 \\
\hline 6 & $\begin{array}{l}\text { Menyusun Berkas Rekam } \\
\text { medis berdasarkan No } \\
\text { Rekam Medis }\end{array}$ & 0,00799387 \\
\hline 7 & $\begin{array}{l}\text { Menerima dan } \\
\text { mengkonfirmasi unit } \\
\text { IRJ,RI, IRD dan unit } \\
\text { lainnya Mengenai BRM } \\
\text { yang di butuhkan Melalui } \\
\text { Telepon }\end{array}$ & 0,00002401 \\
\hline 8 & $\begin{array}{l}\text { Memperbaiki Berkas } \\
\text { Rekam Medis yang } \\
\text { sudah rusak }\end{array}$ & 0,00001601 \\
\hline 9 & $\begin{array}{l}\text { Menyusun Lembar } \\
\text { Rekam Medis }\end{array}$ & 0,01438929 \\
\hline 10 & $\begin{array}{l}\text { Menyusun dan Merapikan } \\
\text { Berkas Rekam Medis di } \\
\text { Rak Penyimpanan }\end{array}$ & 0,00119944 \\
\hline 11 & $\begin{array}{l}\text { Membuat laporan } \\
\text { kegiatan harian }\end{array}$ & 0,0000401 \\
\hline \multicolumn{2}{|c|}{ jumlah } & 0,02416694 \\
\hline
\end{tabular}

Dari hasil perhitungan kebutuhan beban kerja tenaga pada kegiatan penyimpanan berkas rekam medis dengan menggunakan rumus WISN dihasilkan 0,02416694 atau 1 petugas. 
Metode analisis yang pernah digunakan di Rumah Sakit Al-Islam Bandung yaitu analisis beban kerja WISN (Workloud Indicator of Staffing Need). Rumah Sakit Al-Islam sendiri memang cukup dinamis sehingga perhitungan itu menjadi acuan tapi tidak menjadi acuan utama karena pada kenyataannya di lapangan melihat beban kerja dilakukan secara langsung berdasarkan uraian tugas yang ada pada masing-masing posisi. Tetapi uraian tugas pun tidak menjadi uraian yang tetap karena uraian tugas tergantung perubahan-perubahan di masing-masing unit dan kebijakan rumah sakit.

Di Rumah Sakit Al-Islam Bandung setiap kali ada perubahan selalu diadakan evaluasi untuk mengatasi kesalahan jumlah pegawai sehingga menjaga efektivitas dari staf-staf di bagian rekam medis di lihat dari sisi kemampuannya untuk dikerjakan dan dari jumlah staf nya cukup atau tidak. Dalam periode tertentu di terapkan sistem rolling supaya staf tidak merasa jenuh dengan apa yang di kerjakan sehingga staf bisa mencoba sesuatu yang baru dan di sisi lainnya juga menjadi suatu tuntutan bahwa seorang rekam medis itu harus memiliki kompetensi-kompetensi yang standar sebagai seorang rekam medis.

Masalah yang sering kali muncul yaitu kekurangan petugas karena tidak mudah unit untuk mengajukan penambahan petugas, terlebih ketika berbicara tentang efektivitas dengan berbagai macam kendalanya. Namun, disaat adanya Electronic Medical Record tuntutannya sudah tidak ada lagi kekurangan. Yang jadi masalah saat ini adalah bagaimana cara memberikan pemahaman atau semacam upaya untuk melakukan eksplorasi dari kemampuan staf tersebut agar dapat melakukan pekerjaan itu dengan cepat, efektif dan efisien.
Terkait efektivitas di unit penyimpanan, melalui wawancara, dapat diinformasikan dengan diadakannya Electronic Medical Record sangat terasa perubahannya, terutama dari pegawai yang awalnya jumlah 8 orang bertugas di bagian penyimpanan sekarang berkurang menjadi 2 orang dan dari sisi waktu juga sangat terasa perubahannya yang sebelumnya di bagian penyimpanan menerapkan waktu 3 shif yaitu pagi, siang, dan malam saat ini disana hanya ada 2 shif yaitu middle yang pertama bertugas dari jam 07.30 WIB sampai jam 15.30 WIB kemudian yang kedua yaitu jam 09.00 WIB sampai jam 16.10 WIB. Hal tersebut di lakukan karena beberapa pekerjaan yang ada di bagian penyimpanan di hilangkan, salah satunya yaitu kegiatan distribusi. Pada awalnya dilaksanakan kegiatan distribusi berkas rekam medis ke klinik-klinik, namun setelah adanya Electronic Medical Record kegiatan distribusi tersebut di hilangkan, begitu pun ke ruangan karena sebagian masih menggunakan berkas rekam medis fisik karena masih tidak memungkinkan kalau seluruh berkas menggunakan Electronic Medical Record. Seperti halnya berkas-berkas yang terkait dengan legalitas pasien yang harus diisi keluarga atau penanggung jawab pasien contohnya Informed consent, tanda tangan dan yang lainnya.

\section{PENUTUP}

Dari uraian yang telah disampaikan sebelumnya dapat diambil kesimpulan bahwa ketersediaan sumber daya manusia pada bagian penyimpanan sudah cukup hanya saja harus ada perbaikan pada sisi kedisiplinan terutama dalam hal penyelesaian tugas bagi sumber daya manusia tersebut untuk menghindari penumpukan berkas.

Terlebih dengan adanya Electronic Medical Record sangat terasa 
perubahannya, dari pegawai yang jumlahnya 8 orang di bagian penyimpanan dapat berkurang menjadi 2 orang dan dari sisi waktu juga sangat terasa perubahannya

Selain itu pada setiap perubahan perlu dilakukan evaluasi untuk mengatasi kesalahan yang mungkin terjadi, utamanya pada jumlah pegawai setiap unit kerja sehingga menjaga efektivitas dari staf-staf di bagian rekam medis.

\section{DAFTAR PUSTAKA}

A priani, F. (2011). Pengaruh Kompetensi, M otivasi, dan Kepemimpinan terhadap Efektivitas Kerja. Bisnis \& Birokrasi Journal, 16(1).

Budi, S. C. (2011). M anajemen U nit Kerja Rekam Medis. Quantum Sinergi Media.

Cahyono, A. (2015). Hubungan karakteristik dan tingkat pengetahuan Perawat terhadap pengelolaan keselamatan Pasien di rumah sakit. Jurnal IImiah WIDYA, 1(1).

Ernawati, N. L. A. K., Nursalam, N., \& Djuari, L. (2011). Kebutuhan riil tenaga perawat dengan metode W orkload Indicator Staff $N$ eed (WISN ). Jurnal Ners, 6(1), 85-92.

Giyana, F. (2012). A nalisis Sistem Pengel olaan R ekam M edis Rawat Inap Rumah Sakit Umum Daerah Kota Semarang. Jurnal Kesehatan Masyarakat Universitas Diponegoro, 1(2), 18739.

Hasibuan, M. S. (2016). M anajemen sumber daya manusia. Bumi A ksara.

Hatta, G. R. (2012). Pedoman M anajemen Informasi Kesehatan di Sarana Pelayanan Kesehatan: Revisi Buku Petunjuk Teknis Penyelenggaraan Rekam Medis. Medical Record Rumah Sakit (1991) Dan Pedoman
Pengelolaan Rekam M edis Rumah Sakit Di Indonesia (1994, 1997), Edk, 2.

Mujiati, M., \& Yuniar, Y. (2016). Ketersediaan sumber daya manusia kesehatan pada fasilitas kesehatan tingkat pertama dalam era Jaminan Kesehatan Nasional di delapan Kabupaten-Kota di Indonesia. Media Penelitian Dan Pengembangan Kesehatan, 26(4), 201-210.

Mulyani, S. (2017). Sistem Informasi $M$ anajemen Rumah Sakit: Analisis dan Perancangan. Abdi Sistematika.

Murniwati, M. (2012). Peran Rekam M edik Gigi Sebagai Sarana Identifikasi. Majalah Kedokteran Andalas, 36(2), 163-172.

Rosyada, A., Lazuardi, L., \& Kusrini, K. (2016). Persepsi Petugas Kesehatan Terhadap Peran Rekam M edis Elektronik Sebagai Pendukung $M$ anajemen Pelayanan Pasien di Rumah Sakit Panti Rapih. Journal of Information Systems for Public Health, 1(2), 16-22.

Rubbiana, N. I. (2015). A nalisis beban kerja dan kebutuhan tenaga perawat pelaksana dengan metode Workload Indicator Staff Need (WISN) di Instalasi Rawat Inap Tulip RSUD Kota Bekasi Tahun 2015.

Sugiyono. (2012). Metode Penelitian Kuantitatif, Kualitatif dan $\mathrm{R}$ \& D.Bandung:Alfabeta. M etode Penelitian Kuantitatif, Kualitatif $D$ an $R \& D$.Bandung:A lfabeta.https:/ / doi .org/ 10.1017/ CBO9781107415324. 004

Yudhaningsih, R. (2011). Peningkatan efektivitas kerja melalui komitmen, perubahan dan budaya organisasi. Jurnal Pengembangan Humaniora, 11(1), 40-50. 